\title{
Development and assessment of the Alberta Context Tool
}

\section{Carole A Estabrooks*1, Janet E Squires ${ }^{1}$, Greta G Cummings ${ }^{1}$, Judy M Birdsell ${ }^{2}$ and Peter G Norton ${ }^{3}$}

\author{
Address: ${ }^{1}$ Faculty of Nursing, University of Alberta, Edmonton, Alberta, Canada, ${ }^{2}$ On Management Health Group, Calgary, Alberta Canada and \\ ${ }^{3}$ Department of Family Medicine, University of Calgary, Calgary, Alberta, Canada \\ Email: Carole A Estabrooks* - carole.estabrooks@ualberta.ca; Janet E Squires - janet.squires@nurs.ualberta.ca; \\ Greta G Cummings - greta.cummings@ualberta.ca; Judy M Birdsell - jmb@omhg.net; Peter G Norton - norton@ucalgary.ca \\ * Corresponding author
}

Published: 15 December 2009

BMC Health Services Research 2009, 9:234 doi:10.1 186/1472-6963-9-234
Received: 20 June 2009

Accepted: 15 December 2009

This article is available from: http://www.biomedcentral.com/1472-6963/9/234

(C) 2009 Estabrooks et al; licensee BioMed Central Ltd.

This is an Open Access article distributed under the terms of the Creative Commons Attribution License (http://creativecommons.org/licenses/by/2.0), which permits unrestricted use, distribution, and reproduction in any medium, provided the original work is properly cited.

\begin{abstract}
Background: The context of healthcare organizations such as hospitals is increasingly accepted as having the potential to influence the use of new knowledge. However, the mechanisms by which the organizational context influences evidence-based practices are not well understood. Current measures of organizational context lack a theory-informed approach, lack construct clarity and generally have modest psychometric properties. This paper presents the development and initial psychometric validation of the Alberta Context Tool (ACT), an eight dimension measure of organizational context for healthcare settings.

Methods: Three principles guided the development of the ACT: substantive theory, brevity, and modifiability. The Promoting Action on Research Implementation in Health Services (PARiHS) framework and related literature were used to guide selection of items in the ACT. The ACT was required to be brief enough to be tolerated in busy and resource stretched work settings and to assess concepts of organizational context that were potentially modifiable. The English version of the ACT was completed by 764 nurses (752 valid responses) working in seven Canadian pediatric care hospitals as part of its initial validation. Cronbach's alpha, exploratory factor analysis, analysis of variance, and tests of association were used to assess instrument reliability and validity.

Results: Factor analysis indicated a 13-factor solution (accounting for $59.26 \%$ of the variance in 'organizational context'). The composition of the factors was similar to those originally conceptualized. Cronbach's alpha for the 13 factors ranged from .54 to .91 with 4 factors performing below the commonly accepted alpha cut off of .70 . Bivariate associations between instrumental research utilization levels (which the ACT was developed to predict) and the ACT's I 3 factors were statistically significant at the $5 \%$ level for 12 of the 13 factors. Each factor also showed a trend of increasing mean score ranging from the lowest level to the highest level of instrumental research use, indicating construct validity.

Conclusions: To date, no completely satisfactory measures of organizational context are available for use in healthcare. The ACT assesses several core domains to provide a comprehensive account of organizational context in healthcare settings. The tool's strengths are its brevity (allowing it to be completed in busy healthcare settings) and its focus on dimensions of organizational context that are modifiable. Refinements of the instrument for acute, long term care, and home care settings are ongoing.
\end{abstract}




\section{Background}

Organizational context can be defined as "...the environment or setting in which people receive healthcare services, or in the context of getting research evidence into practice, the environment or setting in which the proposed change is to be implemented" [[1], p. 299]. Organizational context is widely considered to be an important influence on the successful implementation of research evidence in healthcare settings [1-4]. However, relatively little empirical evidence exists to support this claim. Further, its measurement has not been adequately addressed. In this paper, we report the first major assessment of a newly developed instrument, the Alberta Context Tool (ACT), designed to parsimoniously measure organizational context as perceived by healthcare providers working in complex healthcare settings.

The Alberta Context Tool (ACT) was developed with a specific purpose in mind and this shaped the approach taken to expanding our understanding of the construct of 'context'. Given our belief that organizational context is a central influence on the effective use of clinically relevant research evidence by healthcare providers, we sought to develop a tool that would allow us to assess context validly and reliably within complex healthcare settings where care is provided to patients. The resulting context measure was intended for administration at the level of the individual healthcare provider to determine their perception of context as it applies to a patient care unit or organization (e.g., hospital), depending on the individual's context of care delivery.

In the development of the ACT we tried to balance, to the extent possible, three principles: a substantive theory, brevity, and modifiability. We used the Promoting Action on Research Implementation in Health Services (PARiHS) framework to conceptualize organizational context. When the framework did not provide direction, we operationalized concepts from related literature (e.g., [5-8]). The PARiHS framework provides a broad conceptualization of how research implementation occurs in organizational settings. In the index paper for PARiHS [9] successful research implementation was proposed to result from the interplay and interdependence of three core elements: (1) evidence, (2) facilitation, and (3) context. We were interested in the context domain.

Context, in the PARiHS framework, is construed generally as the work setting and more specifically embodies three domains: culture, leadership and evaluation. Culture is defined as "the forces at work, which give the physical environment a character and feel" $[9,10]$. Subsequent exploration into the concept of 'culture' by McCormack and colleagues [11] resulted in further refinement of the definition of culture to encompass the prevailing beliefs and values, as well as consistency in these values and a receptivity to change, among members of an organizational setting.

The PARiHS framework defines leadership as the "nature of human relationships" [[11], p.98] with effective leadership giving rise to clear roles, effective teamwork and organizational structures, and involvement by organizational members in decision making and learning. This closely resembles 'transformational leadership'[11], a broad term reflecting leaders thought to be among the most effective leaders because they are able to transpose their ideas and beliefs into collective beliefs which eventually become assumptions and part of a unit's culture [11-13]. Emotionally intelligent leadership styles are one form of leadership consistent with transformational styles because they focus on how leaders manage their own emotions and their relationships with others both individually and in larger social settings [14].

Evaluation is described in the PARiHS framework as feedback mechanisms (individual and system level), sources, and methods for evaluation [9]. Audit (data gathered about the processes and/or outcomes of patient care) coupled with feedback (data provided to members of the organization) is one of the most commonly applied evaluation methods in healthcare organizations. Research implementation is hypothesized by the PARiHS developers to be most successful when evaluation occurs routinely.

A recent paper by the PARiHS group suggests that a fourth contextual component, resources, is important to the implementation of research findings. In 2004, RycroftMalone and colleagues [15] interviewed staff nurses, nurse managers, and other implementation 'experts' at two acute care agencies in the United Kingdom and identified time, equipment, and clinical skills as resources needed to implement research findings. They also identified the complexity of relationships among these resources.

\section{Methods \\ Development of the ACT}

In developing the ACT we worked to make it brief enough to be tolerated in busy and resource stretched work settings. This decision made ACT development of necessity pragmatic. We also chose to focus on concepts of organizational context that were potentially modifiable. Therefore we did not include concepts that could not be a focus of future research implementation intervention studies. Development of the ACT occurred in four phases: (1) selection of the conceptual framework, (2) conceptual refinement, (3) item construction, and (4) feasibility assessment. Time to complete the ACT was assessed as 
part of the feasibility assessment; the ACT was administered to five nurses with a documented mean completion time of 20.7 minutes. Additional detail on the development of the ACT is described elsewhere [16]. Following feasibility assessment, an index version (76 items) of the ACT covering eight dimensions of organizational context was developed. The initial (index) ACT tool was then pretested with 453 healthcare professionals (152 nurses, 36 physicians, 181 allied health professionals, 46 educators and specialists, 38 managers) in four acute care teaching hospitals in Alberta, Canada. Based on this pre-test, the instrument was revised and reduced from 76 to 56 items. Details of the ACT refinement can be found in Additional File 1. The refined ACT consists of 56 items reflecting the following eight contextual dimensions: culture ( 6 items), leadership ( 6 items), evaluation ( 6 items), social capital (6 items), informal interactions ( 7 items), formal interactions (5 items), structural and electronic resources (11 items), and organizational slack (9 items representing three sub-concepts - time, space, human resources). Definitions of the eight context dimensions, along with our hypotheses about their association with research implementation (i.e., research utilization) are listed in Table 1.

The reduced (56-item) version of the ACT was pretested for feasibility and completion time with pediatric nurses in two hospitals in Alberta (Canada). In the pretest, the 56-item ACT was embedded in a larger survey consisting of 135 items and administered to 249 nurses. The mean time to complete the entire survey was 22 minutes for those who completed it online $(n=209)$ and 33 minutes for those who completed it using paper $(n=40)$, resulting in average item to completion times of 9.8 seconds for the online administration and 14.7 seconds for the paper administration. Using this average item time, we estimated a mean time to completion for the 56-item ACT of 9.1 minutes (when administered online) and 13.7 minutes (when administered by paper), both significantly less than time to completion for the original (76-item) version. Based on these completion times, we decided to administer the ACT in the larger multi-site study (reported in this paper) in online format only.

\section{Design, sample, and data collection}

Seven pediatric hospitals in six Canadian provinces provided the sampling pool for the administration of the English version of the refined 56-item ACT (henceforth simply the ACT). Five healthcare professional subgroups were eligible to participate: nurses, physicians, allied professionals, educators/clinical specialists, and managers. Inclusion and exclusion criteria for the professional subgroups are summarized in Additional File 2. Data were collected using an on-line survey. Eligible participants were provided with a survey package containing a letter introducing the study, and a business card providing a
Uniform Resource Locator (URL) and unique password to access the survey on-line.

Ethical approvals for the study were obtained from the appropriate universities and hospital review boards in the respective Canadian provinces.

\section{Data analysis}

Data analyses (except aggregation statistics) were carried out using the Statistical Package for the Social Sciences for Windows (SPSS, v. 16.0) on data collected from professional nurses $(\mathrm{n}=752)$; aggregation statistics were carried out using the SAS 9.2 statistical program. Data analyses included a missing-values analysis; items with missing values greater than 10\% were considered for removal and/ or imputation [17]. Descriptive statistics (variance, mean, histograms) were generated for each item and examined for amount of variance and middle range mean scores as well as sufficient endorsement frequency. Items with a very high or low frequency (endorsement frequency) were considered for elimination since answers can be predicted with frequencies greater than $80 \%$ accuracy and below $20 \%$ [18]. These frequencies would also have no influence on the scale's psychometric properties and may increase burden by making it longer.

\section{Validity}

Since this was the first major field assessment of the ACT, our assessment was largely exploratory rather than confirmatory in nature. Therefore, to examine the underlying dimensional structure of the ACT, we performed factor analysis using principal component analysis (PCA) with orthogonal (Varimax) rotation rather then other factoranalytic methods such as 'principal axis factoring' or 'common factor analysis'. Missing values, which were limited, were treated as such with no substitution or imputation of estimated values. Factors were identified using the 1.0 eigenvalue cutoff rule and the Scree test. Item retention was based on coefficient values (factor loadings $\geq 0.35$ ). Items that cross loaded (factor coefficients $\geq 0.35$ ) on two or more factors were examined on a case-by-case basis and were either re-conceptualized or eliminated from the scale to achieve a balance of good estimation and avoidance of overcapitalizing on sampling error [19]. The Varimax rotation with Kaiser normalization, as recommended by Kline [20], was used to enhance interpretability of the principal component analysis. Following factor analysis, corrected item-total correlations were reviewed for items within the factors identified; items that correlated with the total score below 0.30 were considered for deletion [21]. Items were also considered for deletion if they: (1) caused a significant increase in scale alpha values if they were deleted (item-total statistics), or (2) were highly correlated (>.70 from item-to-item correlations) with each other [22]. 
Table I: Concepts in the ACT survey

\begin{tabular}{|c|c|c|c|}
\hline Concept & Definition & Hypothesis & Sample item \\
\hline Leadership I & $\begin{array}{l}\text { The actions of formal leaders in an } \\
\text { organization (unit) to influence } \\
\text { change and excellence in practice, } \\
\text { items generally reflect emotionally } \\
\text { intelligent leadership }\end{array}$ & $\begin{array}{l}\text { HI: Care providers who perceive } \\
\text { more positive (emotionally } \\
\text { intelligent) unit leadership report } \\
\text { higher research use }\end{array}$ & Calmly handles stressful situations \\
\hline Culture I & $\begin{array}{l}\text { The way that 'we do things' in our } \\
\text { organizations and work units, items } \\
\text { generally reflect a supportive work } \\
\text { culture }\end{array}$ & $\begin{array}{l}\text { H2: Care providers who perceive a } \\
\text { more positive unit culture report } \\
\text { higher research use }\end{array}$ & $\begin{array}{l}\text { My organization effectively } \\
\text { balances best practice and } \\
\text { productivity }\end{array}$ \\
\hline Evaluation ' & $\begin{array}{l}\text { The process of using data to assess } \\
\text { group/team performance and to } \\
\text { achieve outcomes in organizations } \\
\text { or units }\end{array}$ & $\begin{array}{l}\text { H3: Care providers who perceive a } \\
\text { larger number of unit feedback } \\
\text { mechanisms report higher research } \\
\text { use }\end{array}$ & $\begin{array}{l}\text { Our team routinely monitors our } \\
\text { performance with respect to the } \\
\text { action plans }\end{array}$ \\
\hline Social Capital I & $\begin{array}{l}\text { The stock of active connections } \\
\text { among people. These connections } \\
\text { are of three types: bonding, } \\
\text { bridging, and linking }\end{array}$ & $\begin{array}{l}\text { H4: Care providers who perceive } \\
\text { more positive unit social capital } \\
\text { activities report higher research } \\
\text { use }\end{array}$ & $\begin{array}{l}\text { People in the group share } \\
\text { information with others in the } \\
\text { group }\end{array}$ \\
\hline Formal Interactions 2 & $\begin{array}{l}\text { Formal exchanges that occur } \\
\text { between individuals working within } \\
\text { an organization (unit) through } \\
\text { scheduled activities that can } \\
\text { promote the transfer of knowledge }\end{array}$ & $\begin{array}{l}\text { H6: Care providers who perceive a } \\
\text { larger number of formal unit } \\
\text { interactions report higher research } \\
\text { use }\end{array}$ & $\begin{array}{l}\text { How often do these activities } \\
\text { occur? } \\
\text {-Team meetings }\end{array}$ \\
\hline Informal Interactions 2 & $\begin{array}{l}\text { Informal exchanges that occur } \\
\text { between individuals working within } \\
\text { an organization (unit) that can } \\
\text { promote the transfer of knowledge }\end{array}$ & $\begin{array}{l}\text { H5: Care providers who perceive a } \\
\text { larger number of informal unit } \\
\text { interactions report higher research } \\
\text { use }\end{array}$ & $\begin{array}{l}\text { How often do you interact with } \\
\text { people in the following roles or } \\
\text { positions? } \\
\text { - Someone who champions } \\
\text { research and its use in practice }\end{array}$ \\
\hline Structural/Electronic Resources ${ }^{3}$ & $\begin{array}{l}\text { The structural and electronic } \\
\text { elements of an organization (unit) } \\
\text { that facilitate the ability to assess } \\
\text { and use knowledge }\end{array}$ & $\begin{array}{l}\text { H7: Care providers who perceive a } \\
\text { larger number of unit structural and } \\
\text { electronic resources report higher } \\
\text { research use }\end{array}$ & $\begin{array}{l}\text { How often do you use/attend the } \\
\text { following? } \\
\text { - A Library }\end{array}$ \\
\hline Organizational Slack & $\begin{array}{l}\text { The cushion of actual or potential } \\
\text { resources which allows an } \\
\text { organization (unit) to adapt } \\
\text { successfully to internal pressures } \\
\text { for adjustments or to external } \\
\text { pressures for changes }\end{array}$ & & \\
\hline - Human Resources (staffing)। & & $\begin{array}{l}\text { H8: Care providers who perceive } \\
\text { sufficient unit staffing levels report } \\
\text { higher research use }\end{array}$ & Enough staff to deliver quality care \\
\hline - Time 1 & & $\begin{array}{l}\text { H9: Care providers who perceive } \\
\text { having sufficient time on their unit } \\
\text { report higher research use }\end{array}$ & $\begin{array}{l}\text { Time to do something extra for } \\
\text { patients }\end{array}$ \\
\hline - Space I & & $\begin{array}{l}\text { HI0: Care providers who perceive } \\
\text { having sufficient space on their unit } \\
\text { report higher research use }\end{array}$ & Use of designated space \\
\hline
\end{tabular}

I = Scale: I-strongly disagree; 2-disagree; 3-neither agree or disagree; 4-agree; 5-strongly agree

2 = Scale: I-never; 2-rarely; 3-ocasionally; 4-frequently; 5 -almost always

3 = Scale: I-never; 2-rarely; 3-ocasionally; 4-frequently; 5-almost always; 6-not accessible

The ACT was developed to measure organizational context and was motivated by a need to build a better understanding of how to design effective interventions that result in better research uptake. Several studies examining the impact of context on research implementation in both the nursing [2,23-26] and organizational behaviour literature [27] support the importance of contextual factors to research use. We assessed construct validity of the ACT by examining associations between each of its factors and instrumental research utilization. Instrumental research utilization was defined to study participants as the use of observable research-based practices when caring for patients and was scored on a 5-point frequency scale from 1 (use less then $10 \%$ of the time) to 5 (use almost $100 \%$ of the time). This item has been used in several previous studies [28-30]. Items within each ACT concept were averaged (culture, leadership, evaluation, social capital, organizational slack-human resources, organizational slack-time, organizational slack-space) or recoded as existing or not existing and then counted (informal interac- 
tions, formal interactions, structural and electronic resources) to calculate one derived score for each factor.

While research utilization and the ACT variables were measured and analyzed at the individual level in the study reported in this paper, individual scores on the ACT can be aggregated to obtain unit scores by calculating group means. Therefore, we also calculated a set of indices to assess each identified factor's performance when aggregated. One-way analysis of variance (ANOVA) was performed for each variable using the unit as the group variable. The source table from the one-way ANOVA was used to calculate the following indices: (1) interclass correlation ICC $(1)=(B M S-W M S) /(B M S+[K-1] W M S)$, where BMS is the between-group mean square, WMS is the within-group mean square, and $\mathrm{K}$ is the number of subjects per group. The average $\mathrm{K}$ for unequal group size was calculated as $\mathrm{K}=(1 /[\mathrm{N}-1])\left(\Sigma \mathrm{K}-\left[\Sigma \mathrm{K}^{2} / \Sigma \mathrm{K}\right]\right)$; (2) interclass correlation ICC $(2)=(\mathrm{BMS}-\mathrm{WMS}) / \mathrm{BMS} ;(3) \eta^{2}=$ $\mathrm{SSB} / \mathrm{SST}$, where SSB is the sum of squares between groups and SST is the sum of squares total; and (4) $\omega^{2}=(\mathrm{SSB}-[\mathrm{N}$ - 1]WMS)/(SST + WMS). For each variable analyzed, there is strong agreement among nurses in each given unit when ICC (1) is greater than 0.1. Aggregated data are considered reliable when the $F$ statistic from the ANOVA table is statistically significant $(p<0.05)$ and/or ICC (2) is greater than 0.60 [31]. An indicator of effect size is $\eta^{2}$, the proportion of variance in the individual factor accounted for by group membership [32]. Omega squared $\left(\omega^{2}\right)$ is a measure of the relative strength of the aggregated variable at the group level [33]. Both $\eta^{2}$ and $\omega^{2}$ are measures of validity of the aggregated data at the patient care unit level.

\section{Reliability}

Reliability of the factors within the ACT instrument was examined using Cronbach's alpha $(\alpha)$. Factors below the acceptable standard $(0.70)$ for scales intended to compare groups were considered for revision $[21,34]$.

\section{Results}

Sample characteristics

The overall response rate for professional nurses completing the ACT in English was 43.5\% ( $n=764)$. Twelve cases were deleted ( 7 cases for having completed less than $90 \%$ of the survey, and 5 cases for not meeting eligibility criteria) leaving an analytic sample of 752. A summary of the demographic data pertaining to the final sample completing the ACT in English is presented in Table 2.

\section{Missing values and descriptive statistics}

We used listwise deletion to deal with missing data. No individual ACT items were missed by greater than $10 \%$ of

Table 2: Characteristics of Study Sample $(n=752)$

\begin{tabular}{|c|c|c|}
\hline \multicolumn{2}{|c|}{ Demographic Characteristic } & \multirow{2}{*}{$\begin{array}{l}\mathbf{n}(\%) \\
32(4.3)\end{array}$} \\
\hline Gender [n, (\%)] & Male & \\
\hline & Female & $720(95.7)$ \\
\hline & Missing Values & 0 \\
\hline \multirow[t]{11}{*}{ Age [n, (\%)] } & $20-24$ years & $70(9.3)$ \\
\hline & $25-29$ years & $221(29.4)$ \\
\hline & $30-34$ years & $132(17.6)$ \\
\hline & $35-39$ years & $73(9.7)$ \\
\hline & $40-44$ years & $72(9.6)$ \\
\hline & $45-49$ years & $75(10.0)$ \\
\hline & $50-54$ years & $63(8.4)$ \\
\hline & $55-59$ years & $39(5.2)$ \\
\hline & 60-64 years & $6(0.8)$ \\
\hline & $65-70$ years & 0 \\
\hline & Missing Values & $I(0.1)$ \\
\hline \multirow[t]{5}{*}{ Highest Education Level [n, \%] } & Diploma/Certificate & $250(33.2)$ \\
\hline & Bachelors Degree & $488(64.9)$ \\
\hline & Masters Degree & $13(1.7)$ \\
\hline & Other & 0 \\
\hline & Missing Values & $\mathrm{I}(0.1)$ \\
\hline \multicolumn{2}{|c|}{ Number of Years Worked in Current Position [Mean (SD)] } & $8.4(8.3)$ \\
\hline \multicolumn{2}{|c|}{ Number of Years Worked on Unit [Mean (SD)] } & $7.7(7.4)$ \\
\hline \multicolumn{2}{|c|}{ Overall instrumental research utilization score (mean, SD) } & $3.47(1.213)$ \\
\hline
\end{tabular}


respondents. Item distribution of the 56 ACT items showed acceptable variance and middle range mean scores.

\section{Validity - Internal structure}

Factor analysis

Listwise deletion resulted in a final sample of 704 participants for the PCA. The PCA indicated a 13-factor solution accounting for $59.26 \%$ of the variance in 'organizational context'. The range of loadings for each factor, along with the means (and standard deviations) for each factor are shown in Table 3.

Culture, Leadership, Evaluation, Structural and Electronic Resources Culture, leadership, evaluation, and resources constitute organizational context according to the PARiHS framework, which guided the development of the ACT. In our 13-factor solution, the first two factors (eigenvalues 9.806 and 3.825) included all items in the evaluation and leadership subscales and accounted for most of the variance at $17.51 \%$ and $6.83 \%$, respectively. The culture items constituted the seventh factor, (eigenvalue 1.725), accounting for $3.08 \%$ of the variance. Structural and electronic resources were represented in the eighth, ninth, and thirteenth factors (eigenvalues 1.441, 1.406, and 1.042 respectively) and accounted for $2.57 \%, 2.51 \%$, and $1.86 \%$ of the variance respectively in organizational context. Items with the highest factor coefficients were used to name the three 'types' of structural and electronic resources; type 1 (factor 8 ) represented formal resources (e.g., policies and procedures, clinical practice guidelines); type 2 (factor 9) represented traditional resources (e.g., textbooks, journals), and type 3 (factor 13) represented electronic resources (e.g., reminder systems, computerized decision support). Together, culture, leadership, evaluation, and structural and electronic resources (con-

Table 3: ACT Domains: Psychometric Validity and Reliability

\begin{tabular}{|c|c|c|c|c|c|c|c|c|}
\hline \multirow[b]{2}{*}{$\begin{array}{l}\text { Survey } \\
\text { Concept }\end{array}$} & \multirow[b]{2}{*}{ No. Items } & \multirow[b]{2}{*}{$\begin{array}{l}\text { No. } \\
\text { Completed } \\
\text { Responses }\end{array}$} & \multirow[b]{2}{*}{$\begin{array}{c}\text { Mean } \\
\text { Response }\end{array}$} & \multirow[b]{2}{*}{$\begin{array}{l}\text { Standard } \\
\text { Deviation }\end{array}$} & \multicolumn{3}{|c|}{ Factor Analysis' $(n=704)$} & \multirow{2}{*}{$\begin{array}{c}\text { Cronbach } \\
\text { Alpha }^{2}\end{array}$} \\
\hline & & & & & Factor ranks & $\begin{array}{l}\text { Factor } \\
\text { Loadings } \\
\text { (Range) }\end{array}$ & Eigenvalue & \\
\hline Leadership & 6 & 750 & 3.53 & 0.81 & 2 & $0.753-0.842$ & 3.825 & 0.91 \\
\hline Culture & 6 & 746 & 3.83 & 0.53 & 7 & $0.389-0.701$ & 1.725 & 0.72 \\
\hline Evaluation & 6 & 747 & 2.98 & 0.82 & i & $0.774-0.864$ & 9.806 & 0.91 \\
\hline Social Capital & 6 & 742 & 3.90 & 0.47 & 3 & $0.584-0.684$ & 3.412 & 0.77 \\
\hline \multicolumn{8}{|l|}{$\begin{array}{l}\text { Informal } \\
\text { Interactions* }\end{array}$} & 0.60 \\
\hline $\begin{array}{l}\text { Type I- Non- } \\
\text { direct Care } \\
\text { providers }\end{array}$ & 4 & 743 & 1.09 & 0.95 & 4 & $0.550-0.768$ & 2.519 & 0.75 \\
\hline $\begin{array}{l}\text { Type 2- Direct } \\
\text { Care providers }\end{array}$ & 5 & 747 & 4.21 & 0.86 & 5 & $0.339-0.798$ & 2.460 & 0.70 \\
\hline \multicolumn{9}{|l|}{$\begin{array}{l}\text { Structural } \\
\text { and } \\
\text { Electronic } \\
\text { Resources* }\end{array}$} \\
\hline $\begin{array}{l}\text { Type I-Formal } \\
\text { Resources }\end{array}$ & 4 & 745 & 2.74 & 1.00 & 8 & $0.439-0.806$ & 1.441 & 0.71 \\
\hline $\begin{array}{l}\text { Type 2- } \\
\text { Traditional } \\
\text { Resources }\end{array}$ & 3 & 745 & 0.72 & 0.68 & 9 & $0.510-0.720$ & 1.406 & 0.60 \\
\hline $\begin{array}{l}\text { Type 3- } \\
\text { Electronic } \\
\text { Resources }\end{array}$ & 3 & 751 & 1.36 & 0.86 & 13 & $0.602-0.710$ & 1.042 & 0.54 \\
\hline \multicolumn{9}{|l|}{$\begin{array}{l}\text { Organization } \\
\text { al Slack }\end{array}$} \\
\hline Time & 4 & 752 & 2.93 & 0.55 & 6 & $0.606-0.717$ & 1.836 & 0.74 \\
\hline Space & 3 & 750 & 2.94 & 0.88 & 11 & $0.636-0.807$ & 1.232 & 0.63 \\
\hline $\begin{array}{l}\text { Human } \\
\text { Resources }\end{array}$ & 2 & 750 & 2.92 & 1.03 & 12 & $0.759-0.788$ & 1.195 & 0.83 \\
\hline
\end{tabular}

'Extraction Method: Principal Component Analysis, Rotation Method: Varimax method

${ }^{2}$ Cronbach alpha was computed for each individual factor. For factors using a count method for deriving scores (formal interactions, informal interactions [Types I and 2], structural and electronic resources [Types I, 2, and 3]), the recoded values were used to compute Cronbach alpha

* Dimensions derived based on count method 
text according to the PARiHS framework) accounted for $34.36 \%$ of the variance in organizational context as measured by the ACT.

\section{Social Capital}

The third factor (eigenvalue 3.412 ) represented social capital and accounted for $6.09 \%$ of the variance in organizational context as measured by the ACT.

\section{Interactions}

Informal interactions were represented in the fourth and fifth factors (eigenvalues 2.519 and 2.460) and accounted for $4.50 \%$, and $4.39 \%$ of the variance respectively for a total explained variance of $8.89 \%$. Items with the highest factor coefficients were used to name the two 'types' of informal interactions; type 1 (factor 4 ) represented interactions with non-direct care providers (e.g., interactions with a clinical educator, interactions with a quality improvement specialist) while type 2 (factor 5) represented interactions with direct care providers (e.g., interactions with other nurses, hallway talk). Formal interactions (e.g., team meetings, patient rounds) were represented in the tenth factor (eigenvalue 1.286) and accounted for an additional $2.30 \%$ of the variance in organizational context as measured by the ACT.

\section{Organizational Slack}

The sixth, eleventh, and twelfth factors (eigenvalues $1.836,1.232$, and 1.195 respectively) represented the three sub dimensions of organizational slack - time, space, and human resources (staffing). These sub dimensions accounted for $3.28 \%$ (time), $2.20 \%$ (space), and $2.13 \%$ (human resources) of the variance for a combined variance of $7.61 \%$ in organizational context as measured by the ACT.

\section{Item-total statistics}

Corrected item-total correlations for items within each of the 13 factors, with the exception of one item, (continuing education in the formal interaction factor, item-total correlation $=.231$ ) were greater than the predetermined cutoff of .30 indicating items within each factor were related to the overall scale for that factor. Item-total statistics (alpha when item deleted) for each factor also remained stable, providing further internal structure validity evidence for the ACT.

\section{Construct validity}

To assess construct validity of the ACT we examined associations between the 13 ACT factors and levels of the dependent variable (instrumental research utilization). Increases in each of the 13 factors showed a positive bivariate correlation with an increasing trend from lowest level of instrumental research use to the highest (see Table 4). The p-values for both the Pearson's correlation coefficient and the nonparametric Spearman's rank correlation coefficient show a significant bivariate relation between 12 of the 13 ACT factors and instrumental research use at the $5 \%$ level; the only exception was the organizational slackhuman resources factor.

We also assessed the relative percent difference in mean score of each of the ACT's 13 factors from the sample average (Table 4). The results showed a positive incremental relationship with increasing levels of instrumental research utilization (i.e., the higher the contextual scores for each factor assessed relative to the sample average, the better the level of research utilization).

\section{Internal reliability estimations}

Table 3 lists the Cronbach alpha coefficients for each of the 13 factors within the ACT. Coefficients ranged from a low of .54 (for structural and electronic resources - type 3 [electronic resources]) to a high of .91 (for leadership and evaluation factors). With the exception of four factors (structural and electronic resources - type 2 [traditional resources] and type 3 [electronic resources], formal interactions and organizational slack-space) all exceeded the acceptable standard $(>0.70$ ) for scales intended to compare groups recommended by Nunnally and Bernstein [21] and Altman and Bland [34].

\section{Aggregation of the measures to unit level}

The ACT is intended to provide responses that can be aggregated to the level of the patient care unit or to higher organizational levels depending on the context of care delivery for the group(s) completing the instrument. Therefore, we also assessed the performance of the ACT factors when aggregated to the unit level. When developing the ACT, items within the various dimensions were constructed to direct respondents' attention to common experiences on a particular patient care unit in order to ensure that the ACT was meaningful at the unit level. For example, lead-in instructions to the various ACT dimensions asked respondents to assume the shared perspective of their patient care unit (e.g., on my unit we....). Designing items in this way brings about less within-group variability and more between-group variability compared to traditional survey items that focus on individual experiences and perceptions $[35,36]$.

To statistically assess our belief that observations on the ACT are correlated within distinct patient care units, we used four commonly examined aggregation statistics: ICC (1), ICC (2), $\eta^{2}$, and $\omega^{2}$ (see Table 5) [33,37]. The results supported the reliability of aggregating the ACT factors at the patient care unit level:

- ICC(1): The range of ICC(1) values (all greater than $0.00)$ indicate a degree of perceptual agreement among 
Table 4: Assessment of Construct Validity: Correlation of derived ACT factors by increasing levels of instrumental research utilization (IRU)

\begin{tabular}{|c|c|c|c|c|c|c|c|c|}
\hline & \multirow[b]{2}{*}{$\begin{array}{l}\text { Bivariate } \\
\text { correlation } \\
\text { with IRU* }\end{array}$} & \multicolumn{6}{|c|}{$\begin{array}{c}\text { Mean value (or relative } \nabla \% \text { ) of } \mathrm{ACT} \text { factors by increasing levels of instrumental } \\
\text { research utilization }\end{array}$} & \multirow[b]{2}{*}{$\begin{array}{c}\text { P-value for } \\
\text { means } \\
\text { differences }\end{array}$} \\
\hline & & I & 2 & 3 & 4 & 5 & Total ${ }^{\dagger}$ & \\
\hline Leadership & $\begin{array}{l}0.090 * 1 / \\
0.098 * 2\end{array}$ & $3.37(-4.5)$ & $3.45(-2.3)$ & $3.51(-0.6)$ & $3.51(-0.6)$ & $3.68(4.2)$ & 3.53 & $\begin{array}{c}0.069^{3} \\
\left(0.089^{4}\right)\end{array}$ \\
\hline Culture & $\begin{array}{l}0.145^{* * 1} \\
0.148^{* *}\end{array}$ & $3.68(-3.9)$ & $3.75(-2.1)$ & $3.80(-0.8)$ & $3.83(0.0)$ & $3.96(3.4)$ & 3.83 & $\begin{array}{c}0.002 \\
(0.002)^{* *}\end{array}$ \\
\hline Evaluation & $\begin{array}{l}0.130^{* * 1} \\
0.145^{* *}\end{array}$ & $2.64(-11.4)$ & $2.85(-4.4)$ & $3.06(2.7)$ & $2.96(-0.7)$ & $3.15(5.7)$ & 2.98 & $\begin{array}{c}0.000(0.000) \\
* *\end{array}$ \\
\hline Social capital & $\begin{array}{l}0.120 * * 1 \\
0.119 * *\end{array}$ & $3.82(-2.1)$ & $3.83(-1.8)$ & $3.89(-0.3)$ & $3.89(-0.3)$ & $4.02(3.1)$ & 3.90 & $\begin{array}{l}0.009(0.027) \\
* *\end{array}$ \\
\hline $\begin{array}{l}\text { Formal } \\
\text { Interactions }\end{array}$ & $\begin{array}{l}0.154^{* * 1} \\
0.156^{* *}\end{array}$ & $1.49(-19.0)$ & $1.65(-10.3)$ & 1.91 (3.8) & $1.79(-2.7)$ & $2.14(16.3)$ & 1.84 & $\begin{array}{c}0.000(0.000) \\
* *\end{array}$ \\
\hline $\begin{array}{l}\text { Informal } \\
\text { Interactions } \\
\text { (Type I- Non- } \\
\text { Direct Care } \\
\text { Providers) }\end{array}$ & $\begin{array}{l}0.183^{* * 1} \\
0.208^{* *}\end{array}$ & $0.56(-48.6)$ & $0.75(-3 \mid .2)$ & 1.24 (I3.8) & $1.10(0.9)$ & $1.31(20.2)$ & 1.09 & $\begin{array}{c}0.000(0.000) \\
* *\end{array}$ \\
\hline $\begin{array}{l}\text { Informal } \\
\text { Interactions } \\
\text { (Type 2- Direct } \\
\text { Care Providers) }\end{array}$ & $\begin{array}{l}0.196 * * 1 \\
0.220^{* *}\end{array}$ & $3.69(-12.4)$ & $4.04(-4.0)$ & $4.22(0.2)$ & $4.24(0.7)$ & $4.45(5.7)$ & 4.21 & $\begin{array}{c}0.000(0.000) \\
* *\end{array}$ \\
\hline $\begin{array}{l}\text { Structural and } \\
\text { Electronic } \\
\text { Resources } \\
\text { (Type I-Formal } \\
\text { Resources) }\end{array}$ & $\begin{array}{l}0.242^{* * /} \\
0.240^{* *}\end{array}$ & $2.32(-15.3)$ & $2.37(-13.5)$ & $2.76(0.7)$ & $2.77(1.1)$ & $3.13(14.2)$ & 2.74 & $\begin{array}{c}0.000(0.000) \\
* *\end{array}$ \\
\hline $\begin{array}{l}\text { Structural and } \\
\text { Electronic } \\
\text { Resources } \\
\text { (Type 2- } \\
\text { Traditional } \\
\text { Resources) }\end{array}$ & $\begin{array}{l}0.129 * * 1 \\
0.137^{* *}\end{array}$ & 0.5 I (-29.2) & $0.69(-4.2)$ & $0.69(-4.2)$ & $0.73(1.4)$ & $0.89(23.6)$ & 0.72 & $\begin{array}{c}0.003(0.006) \\
* *\end{array}$ \\
\hline $\begin{array}{l}\text { Structural and } \\
\text { Electronic } \\
\text { Resources } \\
\text { (Type 3- } \\
\text { Electronic } \\
\text { Resources) }\end{array}$ & $\begin{array}{l}0.177 * * 1 \\
0.186^{* *}\end{array}$ & I.II (-18.4) & $1.00(-26.5)$ & $1.42(4.4)$ & I.42 (4.4) & $1.56(14.7)$ & 1.36 & $\begin{array}{c}0.000(0.000) \\
* *\end{array}$ \\
\hline $\begin{array}{l}\text { Organizationa } \\
\text { I Slack-Human } \\
\text { resources }\end{array}$ & $0.023 / 0.037$ & $2.76(-5.5)$ & $2.84(-2.7)$ & $2.94(0.7)$ & $3.02(3.4)$ & $2.85(-2.4)$ & 2.92 & $0.25 I(0.289)$ \\
\hline $\begin{array}{l}\text { Organizationa } \\
\text { I Slack-Space }\end{array}$ & $\begin{array}{l}0.149 * * 1 \\
0.158^{* *}\end{array}$ & $2.63(-10.5)$ & $2.84(-3.4)$ & $2.91(-1.0)$ & $2.95(0.3)$ & $3.17(7.8)$ & 2.94 & $\begin{array}{c}0.000(0.001) \\
* *\end{array}$ \\
\hline $\begin{array}{l}\text { Organizationa } \\
\text { I Slack-Time }\end{array}$ & $\begin{array}{l}0.137^{* *} / \\
0.156^{* *}\end{array}$ & $2.68(-8.8)$ & $2.90(-1.4)$ & $2.91(-1.0)$ & $2.97(1.0)$ & $3.04(3.4)$ & 2.94 & $\begin{array}{c}0.000(0.001) \\
* *\end{array}$ \\
\hline
\end{tabular}

* Indicate significance at 0.05 levels.

$* *$ Indicate significance at 0.01 levels.

$\nabla \%$ : Is the \% difference with respect to the total sample average ${ }^{\prime}$

I Spearman's rank correlation coefficients

2 Pearson's correlation coefficients

3 P-value for ANOVA

$4 \mathrm{P}$-value for Kruskal-Wallis test 
Table 5: Aggregation of Data to Patient Care Unit Level

\begin{tabular}{|c|c|c|c|c|c|c|c|c|}
\hline Dimensions & $\mathbf{F}$ & BMS & WMS & $\operatorname{ICC}(1)$ & $\operatorname{ICC}(2)$ & $\operatorname{Eta}^{2}\left(\eta^{2}\right)$ & $\operatorname{Omega}^{2}\left(\omega^{2}\right)$ & PROB \\
\hline IRU & 2.6142 & 3.6288 & 1.3881 & 0.0569 & 0.6175 & 0.0918 & 0.0566 & 0.0000 \\
\hline Leadership & 8.3876 & 4.3897 & 0.5234 & 0.2164 & 0.8808 & 0.2388 & 0.2101 & 0.0000 \\
\hline Culture & 4.2482 & $1.049 \mid$ & 0.2470 & 0.1083 & 0.7646 & 0.1377 & 0.1052 & 0.0000 \\
\hline Evaluation & 6.5082 & 3.6750 & 0.5647 & 0.1708 & 0.8463 & 0.1964 & 0.1660 & 0.0000 \\
\hline Social Capital & 3.1726 & 0.6443 & 0.2031 & $0.075 \mathrm{I}$ & 0.6848 & 0.1071 & 0.0733 & 0.0000 \\
\hline Formal Interactions & 6.4236 & 5.5822 & 0.8690 & 0.1686 & 0.8443 & 0.1948 & 0.1643 & 0.0000 \\
\hline $\begin{array}{l}\text { Informal Interactions } \\
\text { (Type I- Non-Direct Care Providers) }\end{array}$ & 3.2734 & 2.7100 & 0.8279 & 0.0783 & 0.6945 & 0.1100 & 0.0763 & 0.0000 \\
\hline $\begin{array}{l}\text { Informal Interactions } \\
\text { (Type 2- Direct Care Providers) }\end{array}$ & 2.7556 & 1.9098 & 0.6931 & 0.0616 & 0.6371 & 0.0938 & 0.0597 & 0.0000 \\
\hline $\begin{array}{l}\text { Structural and Electronic Resources } \\
\text { (Type I-Formal Resources) }\end{array}$ & 5.4840 & 4.7133 & 0.8595 & 0.1436 & 0.8177 & 0.1712 & 0.1398 & 0.0000 \\
\hline $\begin{array}{l}\text { Structural and Electronic Resources } \\
\text { (Type 2- Traditional Resources) }\end{array}$ & 2.1509 & 0.9533 & 0.4432 & 0.0413 & 0.5351 & 0.0749 & 0.0400 & 0.0007 \\
\hline $\begin{array}{l}\text { Structural and Electronic Resources } \\
\text { (Type 3-Electronic Resources) }\end{array}$ & 5.4422 & $3.477 \mid$ & 0.6389 & 0.1424 & 0.8162 & 0.1689 & 0.1377 & 0.0000 \\
\hline Organizational Slack-Human Resources & 8.5578 & 7.1135 & 0.8312 & 0.2203 & 0.8831 & 0.2424 & 0.2139 & 0.0000 \\
\hline Organizational Slack-Space & 9.9498 & 5.8113 & 0.5841 & 0.2507 & 0.8995 & 0.2712 & 0.2437 & 0.0000 \\
\hline Organizational Slack-Time & 3.5132 & 0.9827 & 0.2797 & 0.0859 & 0.7154 & 0.1158 & 0.0828 & 0.0000 \\
\hline
\end{tabular}

the nurses about the mean values on the ACT factors within each unit. That is, the nurses' perceptions about context within a particular patient care unit were similar.

- ICC(2): All ACT factors showed statistically significant $(p<.05) F$ statistics and ICC(2) values greater than 0.60 (with the exception of structural and electronic resources type 2 [traditional resources]), that is, were we to draw repeated subsequent samples from the same groups (units) we would obtain similar mean scores.

- $\eta^{2}$ and $\omega^{2}$ : However, the relative effect sizes for both $\eta^{2}$ and $\omega^{2}$ values were smaller, suggesting that, as scores on the ACT factors were aggregated, our ability to assign the same meaning for the factor at the unit level as we had at the individual level lessened.

\section{Discussion \\ Reliability}

Experts generally disagree on the precise benchmarks that should be applied to psychometric measures such as alpha coefficients. In part, these benchmarks depend on the application. For example, lower Cronbach alpha coefficients $(.70-.80)$ are deemed acceptable for scales intended to compare groups, while for scales used to measure change within individuals, higher Cronbach alpha coefficients $(>.90)$ are desired $[21,34]$. The internal consistency of the ACT, in terms of the Cronbach's alpha coefficients of its core dimensions, is for the most part, consistent with usual practice for measures intended to be used at the level of the group, or in our case, the patient care unit $[34,38]$. Only 4 of the 13 ACT factors identified in the factor analysis (structural and electronic resources - type 2 [traditional resources], structural and electronic resources
- type 3 [electronic resources], formal interactions and organizational slack-space), had alpha coefficients less than this standard. These lower coefficients may be due to these items addressing concepts that are broader, and perhaps more subject to individual interpretation, than the items in the remaining context concepts.

\section{Validity - Internal Structure}

Factor loadings for all 56 items, with the exception of one item (informal teaching sessions, factor loading $=.339$ ) in the ACT exceeded the minimum cut-off of 0.35 , indicating that items were representative of underlying factors. Some items did not, however, load as expected. The items on how often respondents participate in 'hallway talk' and 'informal teaching sessions' originally part of the dimension of formal interactions loaded with informal interactions. Further, the item on how often respondents participate in 'continuing education', originally part of the structural and electronic resources dimension, loaded with the formal interaction dimension. After careful consideration of these findings the team decided that these loadings were actually a more accurate reflection of the ACT dimensions (as defined in Table 1) that they loaded with and thus we relabelled the item groupings to align with the factor analysis findings.

In developing the ACT we originally hypothesized a 10factor solution (eight contextual dimensions: culture, leadership, evaluation, social capital, informal interactions, formal interactions, structural and electronic resources, and organizational slack (representing three sub-concepts - time, space, human resources)) with items designated for each concept loading onto a single factor. However, two of our contextual concepts turned out to be 
multidimensional, loading onto more than one factor (thus yielding a 13-factor solution). Informal interactions had two factors and structural and electronic resources had three factors indicating more complexity to the construct of organizational context than we had originally proposed.

\section{Construct validity}

The validation process in this study demonstrated beginning empirical support for the construct validity of the ACT. Statistically significant bivariate relationships were found between all but one of the ACT's 13 factors at varying levels of instrumental research utilization. That is, higher levels of research utilization were aligned with more positive contextual conditions. Further analyses showed that the mean scores for each of the ACT's 13 factors varied consistently with a positive incremental association between them and reported research utilization levels. These findings are consistent with the PARiHS framework's assertions (see Table 1) and provide additional empirical support for the construct validity of the ACT.

\section{Aggregation of individual level data to the unit level} Our aggregation statistics indicate that the ACT (when used with professional nurses) can reliably be aggregated to obtain a unit-level assessment of organizational context. We ran the same aggregation statistics with the allied healthcare professionals $(n=209)$ who completed the ACT survey in the study reported in this paper to explore this further. As we had anticipated, the aggregation statistics did not support aggregation of the ACT with the allied professionals at the unit level; ICC(2) was <.60 for all ACT dimensions indicating low reliability of group means when aggregated to the patient care unit level. Given the differences in how work is constructed for nurses and allied professionals this made sense to us. Most nurses perform their work on a single unit, are aligned with that unit and therefore are able to assess and report on common unit practices, beliefs and values causing them to respond similarly on items examining their patient care unit. Allied professionals such as physiotherapists and respiratory therapists, on the other hand, often work across programs (which consist of several units) and therefore should (and do) display greater within unit variability decreasing reliability of their aggregated response. Therefore, at this point in time we only recommend aggregating responses of professional nurses to obtain unit-level scores on the concepts contained within the ACT.

\section{Limitations}

Although the validation results presented in this manuscript are promising, this initial assessment of the ACT was conducted in one country, with one professional group, and with a moderate size sample. Validation of a newly developed instrument such as the ACT is a longitudinal and multi-step process, requiring numerous positive findings, across a variety of applications and settings. Testretest reliability was not assessed, so the ACT's stability is unknown. Cross-validation studies are needed to confirm the factor structure obtained in this initial field test and to establish the reliability and validity of the scales in other samples and settings. Additional validation studies using larger sample sizes will be undertaken as additional data are available; these will permit us to extend our assessment to include confirmatory factor analyses and hierarchical linear modeling.

Additional and much longer term investigation is also needed to explore whether overall scores for the multidimensional ACT concepts (e.g., structural and electronic resources, informal interactions, and organizational slack) can be derived from the instrument. At present we are using overall derived scores for each factor as supported by the factor analysis reported in this paper.

\section{Conclusions}

The findings from this initial validation of the ACT must be interpreted with caution and are not generalizable beyond the sample of nurses reported in this manuscript. Although the overall pattern of the data was consistent with the structure hypothesized in the development of the ACT, some items loaded onto their respective factors less strongly than others. This may indicate that respondents are conceptualizing the individual items within a particular concept somewhat differently than we anticipated. This was not totally unexpected, as for the ACT to be applicable to healthcare professionals across a variety of settings, its items were designed to address the respective dimensions as generically as possible. Preliminary work also suggests the instrument in its current form produces its best aggregated results at the unit level among professional nurses.

Follow-up studies are in progress in which we are assessing the ACT with nurses, allied healthcare professionals, physicians, educators and specialists, and managers in long-term care (nursing home) settings, as well as with unregulated (healthcare aide) workers in long-term care settings. Validation of the instrument within the home care sector is also planned. Additional information on the ACT is available from the lead author of this paper.

\section{Abbreviations}

Commonly used abbreviations in this manuscript include: (1) (ACT): Alberta Context Tool; and (2) (PCA): Principal Components Analysis.

\section{Competing interests}

The authors declare that they have no competing interests. 


\section{Authors' contributions}

CAE, PGN, JMB, and GGC secured the grant that provided funding for the development of the ACT. CAE and PGN led the statistical analytic design presented in the manuscript. JES assisted in performing and in interpreting the statistical analysis, and made substantial contributions to drafting the manuscript. All authors contributed to the development and revision of the manuscript and approved the final version.

\section{Additional material}

\section{Additional file 1}

Act Refinement. A summary of the refinement of ACT from the index (76-item) version to the version piloted.

Click here for file

[http://www.biomedcentral.com/content/supplementary/14726963-9-234-S1.DOC]

\section{Additional file 2}

Inclusion and Exclusion Criteria by Professional Group. A summary of the inclusion and exclusion criteria for the professional subgroups.

Click here for file

[http://www.biomedcentral.com/content/supplementary/1472-

6963-9-234-S2.DOC]

\section{Acknowledgements}

The Alberta Context Tool was developed as part of an Alberta-based study funded by the Alberta Heritage Foundation for Medical Research (AHFMR) (Co-Principal Investigators: CAE and PGN). The authors acknowledge the CIHR Team in Children's Pain (Dr Bonnie Steven's, Principal Investigator) for contributions to this study. Funding for the data used in the validation assessment of the ACT reported in this manuscript was provided by the Canadian Institutes of Health Research (CTP-79854 and MOP-86605). Dr Estabrooks is supported by a CIHR Canada Research Chair in Knowledge Translation. Ms Squires is supported by CIHR, AHFMR, and Killam Fellowships. Dr Cummings holds CIHR New Investigator and AHFMR Population Health Investigator awards. We would like to thank Sung Hyun Kang, MSc (University of Alberta, Canada) for his assistance with statistical analysis, $\mathrm{Dr}$ William Midodzi (University of Alberta, Canada) for his thoughtful input on statistical analyses and drafts, and Dr. Mandi Newton (University of Alberta, Canada) for her assistance with the development of the ACT.

\section{References}

I. Rycroft-Malone J: The PARIHS framework - A framework for guiding the implementation of evidence-based practice. I Nurs Care Qual 2004, 19(4):297-304.

2. Wallin L, Estabrooks CA, Midodzi WK, Cummings GG: Development and validation of a derived measure of research utilization by nurses. Nurs Res 2006, 55(3): $149-160$.

3. Dopson S, FitzGerald L, Ferlie E, Gabbay J, Locock L: No magic targets! Changing clinical practice to become more evidence based. Health Care Manage Rev 2002, 27(3):35-47.

4. Meijers JM, Janssen MA, Cummings GG, Wallin L, Estabrooks CA, R $\mathrm{H}$ : Assessing the relationships between contextual factors and research utilization in nursing: Systematic literature review. J Adv Nurs 2006, 55(5):622-635.

5. Grol R, Berwick $D$, Wensing M: On the trail of quality and safety in health care. BMJ 2008, 336(7635):74-76.
6. Fleuren M, Wiefferink K, Paulussen T: Determinants of innovation within health care organizations: Literature review and Delphi study. Int J Qual Health Care 2004, I6(2): 107-I23.

7. Greenhalgh T, Robert G, Macfarlane F, Bate P, Kyriakidou O: Diffusion of innovations in service organizations: Systematic review and recommendations. Milbank $Q$ 2004, 82(4):58I-629.

8. Grol R, Grimshaw J: From best evidence to best practice: Effective implementation of change in patients' care. Lancet 2003, 362(939I): 1225-| 230.

9. Kitson A, Harvey G, McCormack B: Enabling the implementation of evidence based practice: A conceptual framework. Qual Saf Health Care 1998, 7(3): I49-I58.

10. Rycroft-Malone J, Kitson A, Harvey G, McCormack B, Seers K, Titchen A, Estabrooks C: Ingredients for change: Revisiting a conceptual framework. Qual Saf Health Care 2002, II(2):174-180.

II. McCormack B, Kitson A, Harvey G, Rycroft-Malone J, Titchen A, Seers K: Getting evidence into practice: The meaning of 'context'. J Adv Nurs 2002, 38(1):94-104.

12. Schein EH: Organizational Culture and Leadership San Francisco: JosseyBass Publishers; 1985.

13. Wright J, McCormack B, Coffey A, McCarthy G: Evaluating the context within which continence care is provided in rehabilitation units for older people. International Journal of Older People Nursing 2007, 2(I):9-19.

14. Goleman D, Boyatzis RE, McKee A: The New Leaders: Transforming the Art of Leadership into the Science of Results London: Little, Brown; 2002.

15. Rycroft-Malone J, Harvey G, Seers K, Kitson A, McCormack B, Titchen A: An exploration of the factors that influence the implementation of evidence into practice. J Clin Nurs 2004, 13(8):913-924.

16. Estabrooks CA, Squires JE, Adachi AM, Kong L, Norton PG: Utilization of Health Research in Acute Care Settings in Alberta Technical Report. Edmonton: Faculty of Nursing, University of Alberta; 2008

17. Acock AC: Working with missing data. Family Science Review 1997, I0(I):76-102.

18. Streiner DL, Norman GR: Health Measurement Scales: A Practical Guide to their Development and Use 3rd edition. Oxford: Oxford University Press; 2003.

19. Thompson B: Exploratory and Confirmatory Factor Analysis: Understanding Concepts and Applications Washington, DC: American Psychological Association; 2004.

20. Kline P: An Easy Guide to Factor Analysis London: Routledge; 1994.

21. Nunnally J, Bernstein I: Psychometric Theory 3rd edition. New York: McGraw-Hill; 1994.

22. Betz NE: Test construction. In The Psychology Research Handbook: A Guide for Graduate Students and Research Assistants Edited by: Leong FTL, Austin JT. Thousand Oaks, CA: Sage Publications; 2000:239-250.

23. Angus J, Hodnett E, O'Brien-Pallas L: Implementing evidencebased nursing practice: $A$ tale of two intrapartum nursing units. Nurs Inq 2003, 10(4):218-228.

24. Hunt $M$ : The process of translating research findings into practice. J Adv Nurs 1987, 12:101-I I0.

25. Davies S, McDonnell A, Brown J, Shewan J: Practice nurses' use of evidence-based research. Nurs Times 1999, 95(4):57-60.

26. Estabrooks CA, Midodzi WK, Cummings GG, Wallin L: Predicting research use in nursing organizations: $\mathbf{A}$ multilevel analysis. Nurs Res 2007, 56(4 Suppl):S7-23.

27. Ferlie E, Fitzgerald, Wood M: Getting evidence into clincial practice: An organisational behaviour perspective. J Health Serv Res Policy 2000, 5(2):96-102.

28. Estabrooks CA: The conceptual structure of research utilization. Res Nurs Health 1999, 22(3):203-216.

29. Estabrooks CA, Kenny DJ, Cummings GG, Adewale AJ, Mallidou AA: A comparison of research utilization among nurses working in Canadian civilian and United States Army healthcare settings. Res Nurs Health 2007, 30(3):282-296.

30. Estabrooks CA, Scott S, Squires JE, Stevens B, O'Brien-Pallas L, WattWatson J, Profetto-McGrath J, McGilton K, Golden-Biddle K, Lander J, et al: Patterns of research utilization on patient care units. Implement Sci 2008, 3:31.

31. Glick WH: Conceptualizing and measuring organizational and psychological climate: Pitfalls in multilevel research. Acad Manage Rev 1985, 10(3):601-616. 
32. Rosenthal R, Rosnow RL: Essentials of Behavioural Research: Methods and Data Analysis 2nd edition. New York: McGraw Hill; 199I.

33. Keppel G: Design \& Analysis: A Researcher's Handbook 3rd edition. Englewood Cliffs, NJ: Prentice-Hall; I99I.

34. Altman DG, Bland JM: Statistics notes: Units of analysis. $B M J$ |997, 3 | 4(7098): |874.

35. Klein $\mathrm{KJ}$, Conn $\mathrm{AB}$, Smith $\mathrm{DB}$, Sorra JS: Is everyone in agreement? An exploration of within-group agreement in employee perceptions of the work environment. J Appl Psychol 200I, 86(1):3-16.

36. Vogus TJ, Sutcliffe KM: The Safety Organizing Scale: Development and validation of a behavioral measure of safety culture in hospital nursing units. Med Care 2007, 45(I):46-54.

37. Bliese PD: Within-group agreement, non-independence, and reliability: Implications for data aggregation and analysis. In Multilevel Theory, Research and Methods in Organizations: Foundations, Extensions and New Directions Edited by: Klein KJ, Kozlowski SWJ. San Francisco: Jossey-Bass; 2000:349-38I.

38. Young TL, Kirchdoerfer LJ, Osterhaus JT: A development and validation process for a disease-specific quality of life instrument. Drug Inf J 1996, 30(I): 185-193.

\section{Pre-publication history}

The pre-publication history for this paper can be accessed here:

http://www.biomedcentral.com/1472-6963/9/234/pre pub

Publish with Bio Med Central and every scientist can read your work free of charge

"BioMed Central will be the most significant development for disseminating the results of biomedical research in our lifetime. "

Sir Paul Nurse, Cancer Research UK

Your research papers will be:

- available free of charge to the entire biomedical community

- peer reviewed and published immediately upon acceptance

- cited in PubMed and archived on PubMed Central

- yours - you keep the copyright

Submit your manuscript here:

http://www.biomedcentral.com/info/publishing_adv.asp
BiolMedcentral 